\title{
Governança universitária: um panorama dos estudos científicos desenvolvidos sobre a governança em instituições de educação superior brasileiras
}

\author{
University governance: a overview of scientific studies \\ developed on governance in brazilian higher education institutions
}

\author{
Graziele Alano Gesser ${ }^{1}$ \\ Clésia Maria de Oliveira² \\ Marilia Ribas Machado ${ }^{3}$ \\ Pedro Antônio de Melo ${ }^{4}$
}

Resumo: Este estudo apresenta um panorama dos estudos científicos desenvolvidos acerca da governança nas Instituições de Educação Superior brasileiras e identifica as lacunas no conhecimento nessa área. No que tange à metodologia, trata-se de um estudo predominantemente qualitativo, exploratório, descritivo e bibliográfico, com o emprego da técnica de Revisão Sistemática da Literatura. Realizou-se a busca por artigos em duas bases científicas: Portal de Periódicos da CAPES e Scientific Periodicals Electronic Library (SPELL®), com os constructos governança, universidade e suas variações. Seguindo o protocolo de pesquisa, retornaram a partir da busca um portfólio bibliográfico composto de 153 artigos. Para identificação das pesquisas alinhadas à presente investigação, foi realizada uma nova seleção nessa amostra, a partir da exclusão das publicações duplicadas, leitura dos títulos e resumos, respectivamente, o que resultou em apenas oito artigos para análise. Os resultados mostram que no ano 2006 consta a pesquisa mais antiga e 2015 o ano com maior produção sobre o tema, com três publicações. Contudo, no ano que se seguiu (2016), não houve publicação, o que impossibilita a afirmação de que as discussões sobre governança em IES seja crescente. Uma associação comum entre governança universitária e estratégia ou planejamento estratégico foi evidenciada em três dos oito artigos, o que sugere uma ligação intrínseca entre essas temáticas. Por outro lado, em virtude dos poucos artigos científicos identificados no presente estudo, depreende-se que há carência de investigação científica no Brasil acerca da temática governança universitária.

Palavras-chave: Gestão universitária. Governança universitária. Revisão sistemática da literatura. 
Abstract: This study presents an overview of the scientific studies developed on governance in Brazilian Higher Education Institutions and identifies knowledge gaps in this area. As far as the methodology is concerned, this is a predominantly qualitative, exploratory, descriptive and bibliographic study, using the technique of Systematic Review of Literature. The search for articles in two scientific bases: Portal de Periódicos da CAPES and Scientific Periodicals Electronic Library (SPELL $®)$, with the constructs governance, university and its variations. Following the research protocol, they returned from the search a bibliographic portfolio composed of 153 articles. In order to identify the researches aligned to the present investigation, a new selection was made in this sample, from the exclusion of duplicate publications, reading the titles and abstracts, respectively, which resulted in only eight articles for analysis. The results show that the year 2006 is the oldest and 2015 the year with the highest production on the subject, with three publications. However, in the year that followed (2016), there was no publication, which makes it impossible to assert that the discussions on governance in HEIs are increasing. A common association between university governance and strategy or strategic planning was evidenced in three of the eight articles, which suggests an intrinsic link between these themes. On the other hand, due to the few scientific articles identified in the present study, it is evident that there is a lack of scientific research in Brazil on the subject of university governance.

Keywords: University management. University governance. Systematic review of literature.

${ }^{1}$ Universidade Federal de Santa Catarina | Instituto de Pesquisas e Estudos em Administração Universitária | Florianópolis | SC | Brasil. Contato: graziele.alano@ufsc.br. ORCID: https://orcid.org/0000-0002-5789-1452

${ }^{2}$ Universidade Federal de Rondônia | Departamento de Administração | Porto Velho | RO | Brasil. Contato: clesiamo@unir.br. ORCID: https://orcid.org/0000-0002-0198-7738

${ }^{3}$ Universidade Federal de Santa Catarina | Instituto de Pesquisas e Estudos em Administração Universitária | Florianópolis | SC | Brasil. Contato: marilia.ribas9@gmail.com. ORCID: https://orcid.org/0000-0002-4684-8627

${ }^{4}$ Universidade Federal de Santa Catarina | Instituto de Pesquisas e Estudos em Administração Universitária | Florianópolis | SC | Brasil. Contato: pedro.inpeau@gmail.com. ORCID: https://orcid.org/0000-0001-7607-4303

- Recebido em: 21 dezembro 2018

- Aprovado em: 21 outubro 2020

DOI: http://dx.doi.org/10.1590/S1414-40772021000100002

Este é um artigo publicado em acesso aberto sob uma licença Creative Commons

https://creativecommons.org/licenses/by-nc/4.0/ 


\section{Introdução}

A gestão de uma universidade é uma atividade eminentemente social que deve ser vista como uma perspectiva de contexto e historicidade, que não pode ser apreendida sem ser vivenciada dado que todo seu sentido depende de como são as pessoas que elas vivenciam (GOMES et al., 2013).

No âmbito da Educação Superior, a gestão é um processo importante, porquanto tenha como finalidade derradeira permitir o alcance dos objetivos institucionais (MEYER JÚNIOR; SERMANN; MANGOLIM, 2004). Entretanto, a gestão é justamente uma das funções mais negligenciadas nas Instituições de Educação Superior - IES (MEYER JÚNIOR; SERMANN; MANGOLIM, 2004) e a gestão universitária enquanto prática carece de maior atenção e interpretação por parte dos estudiosos da administração (MEYER JÚNIOR, 2014).

Este artigo é resultante de um estudo sistemático do campo da gestão universitária, cujo objetivo foi apresentar um panorama dos estudos científicos desenvolvidos acerca da governança nas Instituições de Educação Superior e identificar as lacunas no conhecimento sobre essa área. Considerou-se essencial aportar o estudo em um constructo balizado pelas abordagens conjuntas da Gestão Universitária e da Governança Pública, com foco na Governança Universitária. O resultado do estudo tem como propósito apresentar as reflexões dos autores assinalados nos artigos científicos sobre as temáticas governança e universidade, com seus variados constructos.

Para o presente estudo, utilizou-se como metodologia a revisão sistemática de literatura que tem como objetivo responder a uma pergunta claramente formulada utilizando métodos sistemáticos e explícitos para identificar, selecionar e avaliar criticamente pesquisas relevantes e coletar e analisar dados de estudos incluídos na revisão (CLARKE, 2001). Para a revisão sistemática, foram utilizados o Portal de Periódicos da CAPES assim como a base de dados Scientific Periodicals Electronic Library (SPELL®) com os constructos: governança e universidade e suas variáveis.

Considerando a relevância dos estudos sobre o tema, julga-se primordial que as Instituições de Educação Superior (IES) passem a considerar a governança como parte integrante das suas ações.

As Universidades públicas brasileiras são instituições acadêmicas mantidas e vinculadas ao aparelho do Estado e, sendo assim, inserem-se no contexto da Administração Pública, sendo afetadas pelas modificações e interferências que impactam o setor público. Com foco na 
governança pública, um novo marco surgiu com a edição da Instrução Normativa Conjunta CGU/MP nº 001/2016, da Controladoria Geral da União (CGU) e do Ministério do Planejamento, Orçamento e Gestão (MP), que definiu a necessidade dos órgãos e entidades do Poder Executivo Federal em instituir Comitê de Governança, Riscos e Controles. Adicionalmente, após a divulgação desta IN, foi publicado o Decreto n 9.203/2017 dispondo sobre a política de governança da Administração Pública Federal direta e indireta (BRASIL, 2016; 2017).

A sujeição ao contexto da gestão pública instiga as IES públicas a incorporarem novos modelos e paradigmas. Assim, ainda que as IES, em especial as públicas, possuam diversas peculiaridades, essas instituições não prescindem de mecanismos de gestão e governança, como accountability e transparência.

Este estudo inicia-se com o capítulo da introdução, onde há a contextualização e a problematização do tema, seguido pela fundamentação, onde foram abordados tópicos que embasaram o artigo, sendo eles: gestão universitária, governança pública e governança universitária. Após o capítulo da fundamentação é apresentado o capítulo de metodologia, seguido pelos resultados e as considerações finais do estudo.

\section{Fundamentação teórica}

Para propiciar melhor compreensão sobre o fenômeno da governança nas universidades públicas, considerou-se essencial aportar o estudo em um constructo balizado pelas abordagens conjuntas da Gestão Universitária e da Governança Pública, com foco na Governança Universitária.

\subsection{Gestão universitária}

As universidades são caracterizadas como organizações complexas, portadoras de peculiaridades que as diferenciam das demais organizações. A diversidade de objetivos, bem como o tipo de profissionais que nelas atuam e a indissociabilidade do tripé ensino, pesquisa e extensão, fez com que as universidades desenvolvessem um estilo próprio de estrutura, forma de agir e modo de tomar decisão, influenciando, assim, no processo decisório (COLOSSI, 1999).

Dessa forma, a gestão aplicada às universidades tornou-se um recurso de grande valor para essas instituições, visto que, assim como ocorre em outras organizações públicas e privadas, a tomada de decisão é ato contínuo e de alta relevância, por envolver ou impactar 
variados atores, tanto do ambiente interno quanto externo. Jarzabkowski e Fenton (2006) defendem que em organizações pluralistas como as universidades, as preferências são obscuras e a multiplicidade de membros e grupos internos persegue, simultaneamente, objetivos diversos, conflitantes e que concorrem entre si.

Outra contribuição no sentido de apontar elementos da complexidade das organizações universitárias e, consequentemente para a sua gestão, vem dos estudos de Baldridge (1971) Baldridge et al. (1978) citados por Estrada (2000), os quais apresentam como elementos que caracterizam o ambiente universitário: a ambiguidade de metas; o fato de as organizações acadêmicas terem pessoas como elementos centrais do seu processamento; a tecnologia problemática; tarefas econômicas dominadas por um alto profissionalismo; corpo profissional fragmentado; e vulnerabilidade ao ambiente.

\begin{abstract}
A variedade de visões do que deve ser esse tipo de instituição vem, então, desde sua concepção, o que terminou por gerar muitos modelos organizacionais e, muitas formas de gestão. Em que pese essa riqueza de orientações, as universidades vêm se debatendo com a necessidade de encontrar uma forma efetiva de gestão, que as conduzam ao atendimento dessa muitas demandas advindas do ambiente. (REBELO; COELHO; ERDMANN, 2004, p. 156).
\end{abstract}

Diante desse ambiente, visto que segundo Keller (1983), não existe uma teoria da administração universitária, a gestão das universidades tem se valido de modelos e paradigmas criados para outros contextos organizacionais (MEYER, 2014).

Além disso, conforme Kobiyama, Silva e Perardt (2011), a gestão universitária difere daquela de uma empresa, ou organização qualquer, demandando habilidades e domínios de técnicas adequadas à realidade universitária, de modo que as práticas da gestão empresarial sendo ela pública ou privada, não podem ser exportadas diretamente para o setor universitário.

Por este motivo, cabe ao gestor universitário gerenciar suas instituições em direção a um futuro visualizado, decidindo-se pelas questões prioritárias, e gerenciando os possíveis conflitos que surgirem (ÉSTHER, 2011).

Assim, como argumenta Pascuci et al. (2016), é possível concluir que administrar a complexidade interna e externa da organização acadêmica requer uma abordagem diferente das tradicionais que se pautam em premissas funcionalistas e na otimização de resultados. Tal ambiente caótico, desordenado, descontínuo e imprevisível (STACEY, 1996) exige uma postura dinâmica e flexível por parte de seus gestores e a configuração das metodologias de gestão de forma compatível com a realidade e necessidades institucionais.

Nesse sentido, as abordagens sobre Governança Pública, como apresentada no tópico seguinte, trazem um novo olhar sobre as organizações públicas, com uma nova concepção cujo 
foco está centrado no serviço público e no relacionamento dos órgãos e entidades com suas respectivas partes interessadas.

\subsection{Governança pública}

Debates recentes no campo da administração pública apontam para uma nova abordagem que vem sendo construída e que na visão de alguns estudiosos do campo não abandona por completo o modelo gerencialista tão em voga nos anos finais do século XX, mas traz um novo olhar para o serviço público numa perspectiva mais ampla que a conecta a noções de governança. Esse debate tem posicionado os estudiosos e os profissionais do campo, segundo Denhardt (2013) diante de escolhas muitas vezes paradoxais em relação ao futuro da teoria e da prática da administração pública. Ademais, dentro desse debate estão inseridos elementos da governança pública, como pontos-chave na transição para uma forma democrática de relacionamento estado-sociedade com a inclusão de uma cidadania engajada, esclarecida em busca de uma maior participação nas decisões acerca das políticas públicas que afetam toda a sociedade.

Essa nova concepção em discussão desde a década de 1970 e 1980, emerge como New Public Service (NPS) - Novo Serviço Público (NSP) e conforme argumenta Denhardt (2013) é salutar essa construção para que os atores do campo possam caminhar no sentido de cumprir a promessa da administração pública como ciência. E para que isso realmente ocorra, segundo ele, é preciso "de um redirecionamento na maneira como enxergamos o campo e leve à preocupação não meramente com a administração governamental, mas também com o processo mais abrangente de governança e administração da mudança" (DENHARDT, 2013, p. XIV), para, de fato, alcançar valores societários publicamente definidos.

Também enfatiza Denhardt (2013) que, embora os estudos no campo da administração pública tenham sido focados na elaboração de um 'modelo racional de administração' e de uma visão de accountability democrática baseada implicitamente na dicotomia política e administração, os desafios do campo se tornam mais importantes com o foco mais abrangente em governança democrática, por envolver vários atores, deslocando, assim do foco anterior exclusivo no governo. Para fundamentar o NSP, Denhardt (2013) indica dois temas centrais: "promover a dignidade e o valor do novo serviço público" e "reafirmar os valores da democracia, da cidadania e do interesse público enquanto valores proeminentes da administração pública" (p. 265). 
Nessa nova concepção de serviço público, o agente público ou servidor passa a ser um elemento central, pois no NSP, segundo Denhardt (2013), importa a noção de fazer a diferença para tornar o mundo um lugar melhor e, por isso o serviço público “[...] é construído sobre a ideia do interesse público, a ideia de administradores públicos a serviço dos cidadãos [...] totalmente engajados àqueles que o servem" (p. 276).

E com essa orientação e a aproximação com os cidadãos e outros atores envolvidos, como preceitua a governança pública, a criação de valor público socialmente demandado pode vir a se concretizar, com respostas efetivas a três questões básicas: (1) qual o "valor público" importante a organização procura produzir?; (2) quais "fontes de legitimidade e apoio" poderiam ser invocadas para autorizar a organização a tomar medidas e fornecer os recursos necessários para sustentar o esforço para criar esse valor?; e (3) com quais capacidades operacionais a organização poderia contar (ou desenvolver) para entregar os resultados desejados? (MOORE; KHAGRAM, 2004)

Em sentido oposto ao modelo mecanicista burocrático e muito próximo à abordagem ao NSP, a governança pública toma como base os modelos orgânicos, flexíveis, orientados para resultados, com mecanismos amplos de accountability, controle e permeabilidade, em múltiplos arranjos com a participação de diversos atores: estado, terceiro setor, mercado, sociedade, dentre outros, no desenvolvimento, na gestão de políticas públicas e no provimento de serviços (BRASIL, 2014; DIAS, 2012; RAQUEL, 2012; DIAS; CÁRIO, 2014; SECCHI, 2009). O movimento da governança pública (GP) é discutido por Secchi (2009) como um modelo relacional por oferecer "uma abordagem diferenciada de conexão entre o sistema governamental e o ambiente que circunda o governo." (p. 349). Nessa perspectiva de governança pública o Estado tem um papel preponderante de orquestrador, direcionador estratégico, indutor e fomentador essencial para a ativação e orientação das capacidades dos demais atores.

Dias (2012), contribui significativamente com seu estudo ao trazer o que ela denomina elementos da concepção de Governança Pública (quadro 1), constituídos a partir dos trabalhos dos especialistas que estudam as experiências anglo-saxãs e mais comumente referenciados nas publicações brasileiras, como Kooiman (2003), Pierre; Peters (2000) e Rhodes (2010). 


\section{Quadro 1 - Elementos da Governança Pública}

\begin{tabular}{|c|c|}
\hline Elementos da concepção de Governança Pública & $\begin{array}{c}\text { Autores centrais na definição } \\
\text { do elemento }\end{array}$ \\
\hline $\begin{array}{c}\text { E1 - Co-produção do desenvolvimento regional por meio da cooperação entre } \\
\text { Estado, mercado e sociedade civil. }\end{array}$ & $\begin{array}{c}\text { Kooiman (2003); Pierre; Peters } \\
\text { (2000) }\end{array}$ \\
\hline $\begin{array}{c}\text { E2 - Coordenação estatal do processo de cooperação, tendo o Estado um papel } \\
\text { de mediador das relações. }\end{array}$ & $\begin{array}{c}\text { Kooiman (2003); Pierre; Peters } \\
\text { (2000); Rhodes (2010) }\end{array}$ \\
\hline $\begin{array}{c}\text { E3 - Delegação da autoridade estatal em três direções: downward, outward e } \\
\text { upward, reconhecendo o potencial e incentivando o papel das redes. }\end{array}$ & $\begin{array}{c}\text { Pierre; Peters (2000); Rhodes } \\
\text { (2010) }\end{array}$ \\
\hline $\begin{array}{c}\text { E4 - Enfase na eficiência e eficácia associando-as a mecanismos de democracia } \\
\text { deliberativa e democracia direta para a busca de resultados responsivos. }\end{array}$ & $\begin{array}{c}\text { Pierre; Peters (2000) } \\
\text { E5 - Planejamento com vistas à equidade } \\
\text { e ao desenvolvimento regional. }\end{array}$ \\
\hline
\end{tabular}

Fonte: DIAS, Taisa. Governança pública: uma concepção teórico-analítica aplicada no governo do Estado de Santa Catarina a partir da implantação das Secretarias de Desenvolvimento Regional. Tese (Doutorado em Administração) - Universidade Federal de Santa Catarina, Florianópolis, 2012.

Os elementos identificados, como ressalta Dias (2012), são frutos "justamente do fato de a abordagem de um autor transpassar a abordagem de outro, confirmando a presença dele no movimento", isto é, o quadro ilustra o especialista que tem na sua abordagem, "a ênfase naquele elemento, não significando que este não tenha sido tratado na abordagem dos demais especialistas adotados nessa concepção teórica” (p. 137). Em termos de Governança Pública, o deslocamento do poder estatal se concretiza como uma estratégia voltada ao arranjo estrutural do modelo de Administração Pública. Isso é decorrente da manifestação da Governança Pública que se efetiva de maneiras diferentes nos níveis local, nacional e internacional, assim como as instituições e políticas também exercem papéis diferentes em cada um desses níveis (PIERRE; PETERS, 2000; DIAS, 2012).

Como fenômeno, a governança pública pode ser analisada sob quatro perspectivas: sociedade e Estado; entes federativos, esferas de poder e políticas públicas; órgãos e entidades; e atividades intraorganizacionais. Na perspectiva sociedade e Estado são definidas as regras e os princípios que orientam a atuação dos agentes públicos e privados regidos pela Constituição e criam-se as condições estruturais de administração e controle do Estado. Na perspectiva dos entes federativos, esferas de poder e políticas públicas, se observa a partir das políticas públicas e das relações entre estruturas e setores, incluindo diferentes esferas, poderes, níveis de governo e representantes da sociedade civil organizada. Quanto aos órgãos e entidades, nessa perspectivas o foco é na garantia de que cada órgão ou entidade cumpra seu papel; enquanto na perspectiva das atividades intraorganizacionais o foco é na redução dos riscos para otimizar os resultados e agregar valor aos órgãos ou entidades (BRASIL, 2014). 
Em termos práticos, a função da governança, segundo a International Federation of Accountants (IFAC, 2013) é assegurar que as ações das organizações estejam alinhadas com o interesse público. Para isso, sete funções-chaves são definidas, conforme apresentadas no quadro 2.

\section{Quadro 2 - Função da governança e ações alinhadas ao interesse público}

\section{Função da Governança para Alinhamento com o Interesse Público}

(a) a integridade e os valores éticos;

(b) a abertura e o engajamento das partes interessadas;

(c) a definição de resultados e de benefícios sustentáveis em termos econômicos, sociais e ambientais;

(d) a definição de intervenções necessárias para potencializar e otimizar resultados e benefícios;

(e) o desenvolvimento das capacidades das organizações, da liderança e dos indivíduos necessárias àquele fim;

(f) a gestão de riscos e de desempenho sustentado por controles internos e instrumentos robustos de gestão das finanças públicas; e

(g) a transparência e a accountability, possível por meio da implementação de boas práticas, como prestação de contas e responsabilização.

Fonte: adaptado de IFAC (2013)

Embora as funções da governança apresentadas no quadro 2 em muito se assemelhem às inerentes à gestão, no contexto da governança pública há uma distinção entre essas duas, conforme mostra a figura 1 .

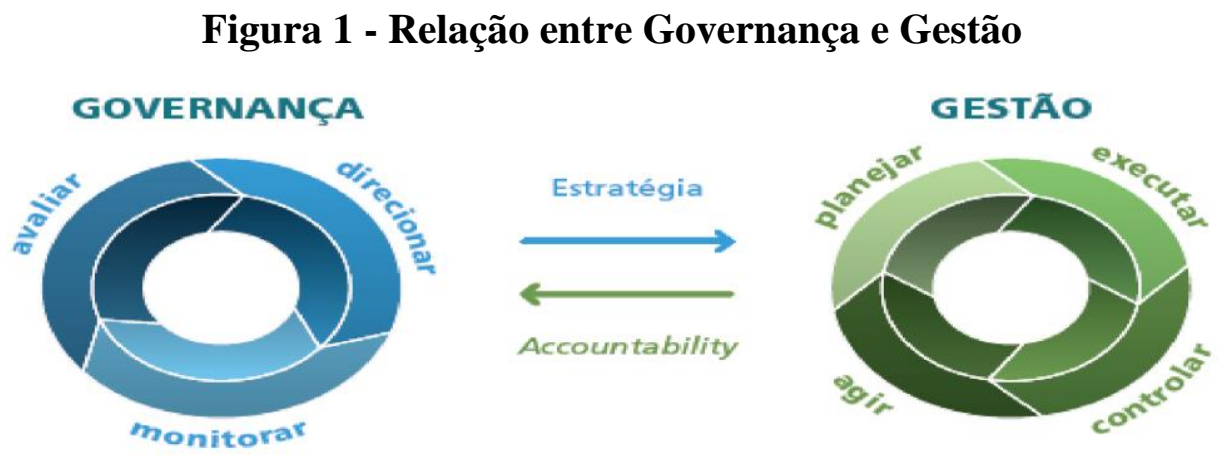

Fonte: BRASIL (2014, p. 32)

Conforme mostra a figura 1, a gestão é responsável pelo planejamento, execução, controle e ação no manejo dos recursos e poderes colocados à disposição do órgão ou entidade pública para alcançar os seus objetivos, enquanto a governança se ocupa em monitorar, supervisionar e avaliar a atuação da gestão, com vistas ao atendimento das necessidades e expectativas dos cidadãos e demais partes interessadas. Dessa forma pode-se inferir que a 
gestão é inerente e integrada aos processos organizacionais e a governança se ocupa em fornecer o direcionamento.

Para abordar o fenômeno da governança pública no contexto organizacional, o próximo tópico apresenta a gestão das instituições de educação superior sob a perspectiva da governança.

\subsection{Governança universitária}

O tema governança universitária é pouco explorado na literatura e é delineado sob as base da governança corporativa e da governança pública, a depender da organização administrativa da IES (se pública ou privada). Segundo Virgili Lillo e Figueroa Aillañir (2016) o conceito de governança universitária formou-se a partir da aplicação da abordagem da governança ao contexto universitário.

Em termos de teorias de aporte à temática governança no contexto universitário, estudo de Virgili Lillo, Ganga Contreras e Figueroa Aillanir (2015) sinalizam como preponderantes: a teoria da agência, teoria dos servidores, teoria dos stakeholders e a teoria da dependência de recursos

Para Balbachevsky, Kerbauy e Fabiano (2016, p. 127) o conceito de governança universitária tem sido usado na literatura a partir de dois pontos de vista distintos: o primeiro focado "nos mecanismos de ajustamento internos à instituição", e o segundo focado "nas estruturas de coordenação que a universidade desenvolve com atores societais externos".

Devido às características das universidades, seu dinamismo, organização e lógica anárquica, "o governo da universidade é, forçosamente, um exercício de governança. Diferentes micro-ambientes institucionais são coordenados através de mecanismos complexos de ajuste que combinam lógicas hierárquicas, de mercado e acordos mútuos" (BALBACHEVSKY; KERBAUY; FABIANO, 2016, p. 128).

Assim, a governança universitária descreve a complexidade dos mecanismos de ajuste mútuo presentes nas IES. Essas instituições se caracterizam pela grande concentração de autoridade, poder e autonomia nas suas unidades. Segundo Dias Sobrinho (1993, p. 54) "O princípio da autonomia se exerce na forma de lei, que, liberdade e restrição, concede e limita". Desta forma, o princípio da autonomia não dicotomiza com o dever das IES em prestar contas à sociedade. Pelo contrário, de acordo com o mesmo autor, a autonomia impõe a exigência de responsabilidade, visto que se dá nos contornos definidos pelas exigências da sociedade e do Estado. 


\section{Metodologia}

Esse artigo teve como objetivo principal apresentar um panorama dos estudos científicos desenvolvidos acerca da governança nas Instituições de Educação Superior e identificar as lacunas no conhecimento sobre essa área.

No que tange à metodologia, trata-se de um estudo predominantemente qualitativo, exploratório, descritivo e bibliográfico, com o emprego da técnica de Revisão Sistemática da Literatura (VERGARA, 2010; FERENHOF; FERNANDES, 2016). Seguindo um protocolo de pesquisa, a busca e revisão sistemáticas possibilitam a obtenção de um portfólio bibliográfico, por meio da identificação e seleção de publicações científicas e posterior coleta e análise dos dados (FERENHOF; FERNANDES, 2016).

Dessa forma, foi realizada uma busca diretamente no Portal de Periódicos da CAPES assim como na base de dados Scientific Periodicals Electronic Library (SPELL®). No Portal de Periódicos da CAPES foram utilizados os seguintes critérios de busca: busca simples contendo as palavras-chave e operadores booleanos: governança and ("Universitária" OR "universidade” OR “IES” OR “ensino superior” OR “educação superior”); Tipos de recursos artigo; Tópico Brazil; Idioma Português. Retornaram, com a busca, 153 artigos. A partir daí, para identificação das pesquisas alinhadas à presente investigação, foi realizada uma nova seleção, com a exclusão das publicações duplicadas, leitura dos títulos e resumos, respectivamente. Após esse procedimento, verificou-se que 4 (quatro) artigos efetivamente discutiam a temática proposta nessa pesquisa.

Já a busca na base de dados SPELL®, seguiu os seguintes critérios: resumo contendo as palavras-chave e operadores booleanos: Governança E Universitária; Governança E Universidade; Governança E IES; Governança E Ensino Superior; Governança E Educação Superior; Tipos de documentos artigo; Idioma Português. Ao final, as buscas retornaram 39 artigos científicos. Também foi realizada uma nova seleção a partir da leitura dos títulos, resumos e exclusão das publicações duplicadas. Finda tal filtragem 4 (quatro) artigos compuseram a segunda parte da amostra dessa investigação.

Considerando as duas plataformas de busca, selecionou-se 8 (oito) artigos científicos que efetivamente discutem a temática governança no contexto das Instituições de Ensino Superior, demonstrando que há ainda uma lacuna teórica a ser explorada pelos pesquisadores da gestão universitária.

Com o intuito de identificar a contribuição de cada estudo, a reflexão dos autores sobre a temática e as lacunas de pesquisa, foi feita a leitura da seção intitulada conclusões ou 
considerações. A leitura da seção visou a identificação de oportunidades de pesquisa na área, indicadas pelas sugestões para trabalhos futuros

\section{Resultados}

Por meio da análise dos artigos, observou-se que nenhum autor escreveu mais do que um artigo científico e que todos os artigos foram publicados em periódicos diferentes. Apesar de não ter sido definido limite temporal para a busca sistemática nas duas plataformas utilizadas, o artigo mais antigo foi publicado em 2006. Três dos 8 (oito) artigos foram publicados em 2015, ano com maior produção científica sobre o tema. Em relação à representatividade, segundo dados coletados no Google Acadêmico, o artigo mais citado teve 14 citações: Sistema Nacional de Avaliação da Educação Superior: oportunidades para a responsabilidade social na gestão estratégica de instituições de ensino superior (ASHLEY; FERREIRA; REIS, 2007).

As principais considerações e reflexões dos autores sobre a temática, assinaladas nos artigos científicos são apresentadas a seguir:

a) o tema governança envolve a criação de forças organizacionais, que garantem o sucesso dos stakeholders e da sociedade; mesmo nas IES mais "fechadas", diversos stakeholders influenciam as estratégias das IES; o sucesso ou fracasso das estratégias e os benefícios propiciados aos stakeholders são de total responsabilidade da IES e de seus tomadores de decisões (TEIXEIRA; DE CASTRO, 2015);

b) as instituições de ensino são complexas, controversas e possuem adversidade, demandando por mais estudos para melhor entendimento; a Teoria Ator-Rede contribui para a teoria das redes de governança, sendo a incorporação da compreensão dos atores não humanos, inserida na primeira teoria, uma de suas principais contribuições a última; são importantes as atividades e práticas estratégicas analisadas que se relacionam aos mecanismos e às redes de governança (MONTENEGRO; BULGACOV, 2015);

c) a inovação requer ambientes especializados e cooperativos, porém a formação de alianças estratégicas visando a cooperação nem sempre é convergente com a demanda por competitividade inerente ao processo de inovação para o mercado; o potencial de desenvolvimento de cada estado depende da existência de uma rede estadual de Instituições de Ensino Superior com atividades de pós-graduação ou de uma rede estadual de Instituições de Ciência e Tecnologia (ICTs); a ausência dessas redes, limita a capacidade dos estados de fazer uso estratégico do fomento federal; o Programa de Apoio à Pesquisa em Empresas (PAPPE) apresenta problema como demora na implementação efetiva, deficiências organizacionais, ambiguidade quanto às fronteiras institucionais; o monitoramento e avaliação dos programas ainda não estão internalizados (BOTELHO; ALMEIDA, 2012);

d) a relevância estratégica do modelo de governança desenvolvido entre as duas instituições consiste na contribuição para o desenvolvimento regional, em termos de recursos humanos e inovações tecnológicas; o arranjo em redes interorganizacionais possibilita a equalização do desenvolvimento científico regional; a governança 
fortaleceu o relacionamento institucional e criou condições para a IES se destacar entre as ICTs (POLLETO; ARAÚJO; MATA, 2011);

e) a evolução da governança corporativa da Universidade familiar divide-se em dois grandes períodos: primeiro, marcado pela justaposição entre mantenedora e mantida; e o segundo, com separação entre ambas; o primeiro período caracteriza-se pela falta de controle de dados; o segundo período, marcado pela profissionalização da gestão universitária, altera o ambiente político da IES e gera uma arena marcada pelos conflitos de interesses e problemas de agência; como consequência do problema de agência, e da necessidade de controle da propriedade sobre a gestão, há incidência de custos de agência (DA SILVA JUNIOR; MUNIZ; MARTINS, 2009);

f) estruturas de governança que promovam valores e princípios éticos, transparência e comunicação organizacional revelam a responsabilidade social das IES; uma instituição/organização socialmente responsável requer a responsabilidade social também dos seus stakeholders, os quais devem valorizar a conduta responsável da instituição (ASHLEY; FERREIRA; REIS, 2007);

g) dado o importante papel social das IES, nessas instituições é crescente a importância da governança, transparência e prestação de contas; a exigência por maior responsabilidade social impulsiona as IES a buscarem atender às boas práticas de governança; apesar das oportunidades de ampliação de práticas de responsabilidade social, muitas IES possuem um posicionamento reativo em relação a essas estratégias; as IES se mostram mais instigadas a atender à legislação do que demonstrar mais transparência à sociedade; mesmo assim, nem todos os aspectos legais são identificados pela pesquisa em algumas IES, o que não sinaliza que estes não sejam seguidos (LENNAN; SEMENSATO; OLIVA, 2015);

h) processo de planejamento estratégico recente; não obstante a existência de iniciativas voltadas para a execução do planejamento, há fragilidades no seu acompanhamento além de não haver participação da sociedade neste acompanhamento; há descontinuidade de iniciativas e projetos; há preocupação de como a IES pode contribuir com o desenvolvimento regional; presença de características de governança pública, tais como preocupação com o atendimento de demandas sociais e aderência à ideia de bem comum; valorização de redes e parcerias (governo federal, órgãos estatais e setor privado); e elementos de democracia e transparência (consultas públicas), contudo sem acompanhamento constante por parte da sociedade, imprescindível aos preceitos democráticos; gestão fortemente marcada pelo paradigma gerencialista, não considerando tanto os aspectos sociais; a transparência e a participação democrática ainda não estão consolidadas na execução do planejamento estratégico da IES (HENN et al., 2017).

Nem todos os artigos analisados identificaram possíveis lacunas no conhecimento acerca do tema. Entretanto, as oportunidades de pesquisa sobre governança em Instituições de Educação Superior, derivadas das sugestões para pesquisas futuras indicadas nos artigos científicos são apresentadas a seguir:

a) analisar o tema governança - redes de governança, estratégia como prática socialstrategizing-resultados estratégicos e Teoria Ator-Rede em cursos de graduação em IES 
particulares por meio de estudo etnográfico com intuito de aprofundar as questões desta temática (MONTENEGRO; BULGACOV, 2015);

b) analisar o tema governança - redes de governança em outro campo de pesquisa, por exemplo em entidades públicas ou em empresas mistas (MONTENEGRO; BULGACOV, 2015);

c) investigar o escopo da relação entre atores humanos e não humanos, na perspectiva do sustentabilidade e do empreendedorismo;

d) investigar a existência de diferenças regionais e de porte organizacional nos processos de governança (MONTENEGRO; BULGACOV, 2015);

e) mais investigações sobre a problemática do relacionamento entre mantenedora e mantida e governança em IES familiar (DA SILVA JUNIOR; MUNIZ; MARTINS, 2009);

f) realizar discussão sobre o enquadramento reduzido que a lei que instituiu o Sistema Nacional de Avaliação da Educação Superior (SINAES) define e restringe a uma única dimensão o conceito de responsabilidade social das IES (ASHLEY; FERREIRA; REIS, 2007);

g) analisar a dinâmica do sistema de gestão sob a ótica da transparência e da governança por meio de estudos de casos (LENNAN; SEMENSATO; OLIVA, 2015);

h) replicar o modelo de análise do estudo (combinação do framework de Responsabilidade Social Empresarial com as Boas Práticas de Governança) em investigação em outras fundações e associações sem fins lucrativos (LENNAN; SEMENSATO; OLIVA, 2015);

i) realizar estudo para levantamento de informações junto a comunidade, permitindo a ampliação da visão de planejamento para além dos gestores e dos dirigentes da instituição (HENN et al., 2017);

j) realizar pesquisas sobre a temática em outros órgãos públicos (HENN et al., 2017).

Com a identificação dessas lacunas, finaliza-se a análise dos resultados e, na próxima seção são apresentadas as considerações finais do presente estudo.

\section{Considerações}

Esta pesquisa teve como objetivo principal apresentar um panorama dos estudos científicos desenvolvidos acerca da governança nas Instituições de Educação Superior e identificar as lacunas no conhecimento sobre essa área.

Apesar de não ter sido definido limite temporal para a busca sistemática nas duas plataformas utilizadas, a pesquisa mais antiga foi publicada em 2006, o que comprova que o tema Governança Universitária foi introduzido recentemente nas discussões acadêmicas brasileiras. 
Além disso, em virtude dos poucos artigos científicos identificados no presente estudo, depreende-se que há carência de investigação científica no Brasil acerca da temática governança universitária. Em 2015, houve a maior produção científica sobre o tema, com publicação de 3 (três) dos 8 (oito) artigos componentes da análise dessa pesquisa. Porém, no ano que se seguiu não houve publicação alguma, o que impossibilita a afirmação de que as discussões sobre governança em IES é crescente.

Em alguns artigos, uma associação comum foi entre governança universitária e estratégia ou planejamento estratégico (TEIXEIRA; DE CASTRO, 2015; MONTENEGRO; BULGACOV, 2015, HENN et al., 2017), e também entre governança universitária e responsabilidade social (ASHLEY; FERREIRA; REIS, 2007; LENNAN; SEMENSATO; OLIVA, 2015), o que sugere uma intrínseca ligação entre essas temáticas.

Como mencionado, há carência de investigação científica no Brasil acerca da temática governança universitária e, como consequência, há lacunas de conhecimento a serem preenchidas. Como recomendações para estudos futuros sugerem-se:

a) analisar a governança universitária sob a perspectiva das diferentes atividades acadêmicas e administrativas;

b) investigar a relação entre a governança universitária e outras temáticas relevantes para o campo, ainda em construção, da Gestão Universitária, tais como sustentabilidade, empreendedorismo, internacionalização, conflitos, relacionamento com as partes interessadas, responsabilidade social e compliance.

c) verificar o impacto de fatores não-humanos na governança universitária;

d) analisar a governança universitária segundo a percepção de diferentes atores sociais.

Assim, o presente estudo cumpriu o seu objetivo ao apresentar um panorama dos estudos científicos desenvolvidos acerca da governança nas Instituições de Educação Superior brasileiras, com a identificação de algumas lacunas no conhecimento sobre a temática, a partir do portfólio analisado, o que permitiu também apontar as recomendações para estudos futuros acima sugeridos. Dessa forma, conclui-se com o presente estudo que a Governança Universitária é temática relevante, sobretudo no contexto atual brasileiro, de escassez de recursos e incertezas quanto às políticas públicas para a educação superior.

\section{Referências}

ASHLEY, Patrícia Almeida; FERREIRA, Roberto do Nascimento; REIS, Helvécio Luiz. Sistema Nacional de Avaliação da Educação Superior: oportunidades para a responsabilidade 
social na gestão estratégica de instituições de ensino superior. Revista Ibero-Americana de Estratégia, São Paulo, v. 5, n. 1, p. 23-35, 2007.

BALBACHEVSKY, Elizabeth; KERBAUY, Maria Teresa; FABIANO, Neylor de Lima. A Governança universitária em transformação: a experiência das universidades públicas brasileiras. In: KOGA-ITO, Cristiane Y.; LUCA, Tania R. de. Escola UNESP de liderança e gestão: instrumento para excelência da gestão institucional. São Paulo: Cultura Acadêmica, p. 125-138, 2016.

BALDRIDGE, J. Victor. Power and conflict in the university: research in the sociology of complex organizations. New York: John Wiley \& Sons, 1971.

BALDRIDGE, J. Victor et al. Policy making and effective leadership. San Francisco: Jossey-Bass Publishers, 1978.

BOTELHO, Antônio; ALMEIDA, Mariza. Desconstruindo a política científica no Brasil: evolução da descentralização da política de apoio à pesquisa e inovação. Sociedade e Estado, Brasília, v. 27, n. 1, p. 117-132, 2012.

BRASIL. Tribunal de Contas da União (TCU). Governança Pública: referencial básico de governança aplicável a órgãos e entidades da administração pública e ações indutoras de melhoria. Brasília: TCU, Secretaria de Planejamento, Governança e Gestão, 2014.

BRASIL. Instrução Normativa Conjunta CGU/MP Nº 001, de 10 de maio de 2016.

Dispõe sobre controles internos, gestão de riscos e governança no âmbito do Poder Executivo Federal. Ministério do Planejamento, Orçamento e Gestão/Controladoria Geral da União: DF, 2016.

BRASIL. Decreto n⿳ 9.203, de 22 de Novembro de 2017. Dispõe sobre a política de governança da administração pública federal direta, autárquica e fundacional. 2017. Disponível em: <http://www.planalto.gov.br/ccivil_03/_ato20152018/2017/decreto/D9203.htm>. Acesso em: 15 fev. 2018.

CLARKE, Horton R. Bringing it all together: Lancet-Cochrane collaborate on systematic reviews. The Lancet, Reino Unido: Oxford Elsevier, v. 357, n. 9270, p. 1777-1789, 2001.

COLOSSI, Nelson. Controle da gestão na universidade: algumas considerações. In: ENCUENTRO REGIONAL NOA SOBRE EVALUACIÓN DE LA EDUCACIÓN SUPERIOR, 1999, San Miguel de Tucumán. Anais [...] Universidad Nacional de Tucumán. San Miguel de Tucumán, Argentina, 1999.

DA SILVA JUNIOR, Annor; MUNIZ, Reynaldo Maia; MARTINS, Priscilla de Oliveira. Governança corporativa na IES familiar de grande Porte: um estudo de caso. Revista Alcance, Biguaçu, v. 16, n. 3, 2009.

DENHARDT, Robert B. Teorias da administração pública. São Paulo: Cengage Learning, 2013.

DIAS, Taisa. Governança pública: uma concepção teórico-analítica aplicada no governo do Estado de Santa Catarina a partir da implantação das Secretarias de Desenvolvimento 
Regional. Tese (Doutorado em Administração). Universidade Federal de Santa Catarina, Florianópolis, 2012.

DIAS, Taisa; CÁRIO, Silvio A. F. Sociedade, desenvolvimento e o papel estratégico do Estado: uma reflexão sobre o surgimento da Governança Pública. Ensaios FEE, Porto Alegre, v. 35, n. 2, p. 337-362, dez. 2014

DIAS SOBRINHO, José. Autonomia universitária. Pro-Posições, Campinas, v. 4, n. 2, p. 5359, jul. 1993.

ÉSTHER, Ângelo Brigato. As competências gerenciais dos reitores de universidades federais em Minas Gerais: a visão da alta administração. Cadernos EBAPE.BR, Rio de Janeiro, v. 9, Edição Especial, p. 648-667, jul. 2011. Disponível em:

http://www.scielo.br/scielo.php?script=sci arttext\&pid=S1679-

39512011000600011\&lng=en\&nrm=iso. Acesso em: 18 ago. 2017.

ESTRADA, Rolando Juan S. Os rumos do planejamento estratégico na universidade pública. 2000. 206 f. Tese (Doutorado em Engenharia da Produção) - Centro Tecnológico, Universidade Federal de Santa Catarina, Florianópolis, 2000.

FERENHOF, Helio Aisenberg; FERNANDES, Roberto Fabiano. Desmistificando a revisão de literatura como base para redação científica: método SFF. Revista ACB, São José, SC, v. 21, n. 3, p. 550-563, 2016.

GOMES, Osmailda da Fonseca et al. Sentidos e implicações da gestão universitária para os gestores universitários. Revista GUAL, Florianópolis, v. 6, n. 4 Edição Especial, p. 234-255, 2013.

HENN, Sara Abreu et al. Planejamento estratégico de uma instituição de ensino superior federal brasileira: uma análise à luz do movimento da governança pública. Revista

Organizações em Contexto, São Bernardo do Campo, v. 13, n. 25, p. 219-243, 2017.

Disponível em: https://www.metodista.br/revistas/revistas-

metodista/index.php/OC/article/view/7395. Acesso em: 15 ago. 2017.

IFAC. International Federation of Accountants. Good governance in the public sector: consultation draft for an international framework, 2013. Disponível em:

https://www.ifac.org/knowledge-gateway/contributing-global-

economy/publications/international-framework-good-governance-public-sector. Acesso em: 1 mar. 2017.

JARZABKOWSKI, Paula; FENTON, Evelyn. Strategizing and organizing in pluralistic contexts. Long Range Planning, United Kingdom, v. 39, p. 631-648, 2006. Disponível em: https://www.sciencedirect.com/science/article/abs/pii/S002463010600094X. Acessi em: 1 mar. 2017.

KELLER, G. Academic strategy. Baltimore: Johns Hopkins University Press, 1983.

KOBIYAMA, Adriana R. C. E.; SILVA, Elizabeth C. R. e; PERARDT, Susany. O Mestrado Profissional em Administração Universitária da Universidade Federal de Santa 
Catarina: um estudo de caso sobre o processo de criação e implantação. 2011. Disponível em: https://repositorio.ufsc.br/handle/123456789/32856. Acesso em: 15 ago. 2017.

KOOIMAN, J. Governing as governance. Londres: Sage, 2003.

LENNAN, Maria Laura Mac; SEMENSATO, Bárbara Ilze; OLIVA, Fábio Lotti.

Responsabilidade social empresarial: classificação das instituições de ensino superior em reativas ou estratégicas sob a ótica da governança corporativa. REGE-Revista de Gestão, São Paulo, v. 22, n. 4, p. 457-472, 2015.

MEYER JÚNIOR, Victor. A prática da administração universitária: contribuições para a teoria. Universidade em Debate, Paraná, v. 2, p. 1-15, dez. 2014. Disponível em: http://www2.pucpr.br/reol/pb/index.php/universidade?dd1=14749\&dd99=view\&dd98=pb. Acesso em: 18 ago. 2017.

MEYER JÚNIOR, Victor; SERMANN, Lúcia; MANGOLIM, Lúcia. Planejamento e gestão estratégica: viabilidade nas IES. In: COLÓQUIO INTERNACIONAL SOBRE GESTÃO UNIVERSITÁRIA NA AMÉRICA DO SUL, 4, 2004, Mar del Plata, Argentina. Anais [...]. Florianópolis, INPEAU, 2004. Disponível em: https://repositorio.ufsc.br/bitstream/handle/123456789/35823/Victor\%20Meyer\%20Jr\%20$\% 20$ Planejamento $\% 20 \mathrm{e} \% 20 \mathrm{Gest} \% \mathrm{C} 3 \% \mathrm{~A} 3 \mathrm{o} \% 20 \mathrm{Estrat} \% \mathrm{C} 3 \%$ A9gica.pdf?sequence $=4 \&$ isAllo wed=y. Acesso em: 15 fev. 2017.

MONTENEGRO, Ludmilla Meyer; BULGACOV, Sergio. Governança e estratégia de cursos de graduação em administração na perspectiva da Teoria Ator-Rede. RAC-Revista de Administração Contemporânea, Rio de Janeiro, v. 19, n. 2, 2015.

MOORE, Mark; KHAGRAM, Sanjeev. On creating public value: what business might learn from government about strategic management. Corporate Social Responsability Initiative Working Paper No.3. Cambridge, MA: John F. Kennedy School of Government, Harvard University, 2004.

PASCUCI, Lucilaine et al. Managerialism na gestão universitária: implicações do planejamento estratégico segundo a percepção de gestores de uma universidade pública. Revista GUAL, Florianópolis, v. 9, n. 1, p. 37-59, jan. 2016.

PIERRE, J.; PETERS, B. G. Governance: politics and the State. Houndmills: MacMillan Press, 2000.

POLLETO, Carlos Alberto; ARAÚJO, Maria Arlete de; MATA, Wilson da. Gestão compartilhada de P\&D: o caso da Petrobras e a UFRN. Revista de Administração Pública, Rio de Janeiro, v. 45, n. 4, p. 1095-1117, 2011.

RAQUEL, Izabela. Governança pública: a consolidação de uma matriz com atributos que caracterizam o tema, na perspectiva de especialistas. 2012. 173 p. Dissertação (Mestrado) Programa de Pós-Graduação em Administração, Universidade Federal de Santa Catarina, Florianópolis, 2012.

REBELO, Luiza Maria B.; COELHO, Christianne C. S. R.; ERDMANN, Rolf Hermann. Contribuições da Teoria da Complexidade ao Processo de Planejamento Estratégico em 
Universidades. In: MELO, Pedro Antônio de; COLOSSI, Nelson. Cenários da gestão universitária na contemporaneidade. Florianópolis: Insular, 2004.

RHODES, R. A. W. Understanding governance: policy networks, governance, reflexivity and accountability, Philadelphia, US, Open University Press, 2010.

SECCHI, Leonardo. Modelos organizacionais e reformas da administração pública. Revista de Administração Pública, Rio de Janeiro, v. 43, n. 2, p. 347-369, 2009.

STACEY, R. D. Strategic management and organisational dynamics. London: Pitman Publishing, 1996.

TEIXEIRA, José Franco; DE CASTRO, Luis Mota. Questões de governança e os papéis dos stakeholders no ambiente do ensino superior brasileiro. Revista Gestão Universitária na América Latina - GUAL, Florianópolis, p. 237-257, maio 2015.

VERGARA, Sylvia Constant. Projetos e relatórios de pesquisa em administração. 12. ed. São Paulo: Atlas, 2010.

VIRGILI LILLO, Mariol; GANGA CONTRERAS, Francisco; FIGUEROA AILLANIR, Katherine. Gobernanza universitaria o cogobierno: el caso de la Universidad de Concepción de Chile. Ultima década, Santiago, v. 23, n. 42, p. 187-216, jun. 2015. Disponível em: https://ultimadecada.uchile.cl/index.php/UD/article/view/56196/59412. Acesso em: 15 ago. 2017.

VIRGILI LILLO, Mariol; FIGUEROA AILLAÑIR, Katherine. Formas de elección de rectores en las universidades tradicionales privadas chilenas: una propuesta de investigación. Educação, Ciência e Cultura, Canoas, v. 21, n. 2, p. 75-102, dez. 2016. Disponível em: http://www.revistas.unilasalle.edu.br/index.php/Educacao/article/view/22366377.16.33/pdf. Acesso em: 15 ago. 2017. 